\title{
NOÉMIA DE SOUSA: \\ UM “BLUES" MOÇAMBICANO PARA BiLLIE HOLIDAY
}

Márcio Aparecido da Silva de Deus ${ }^{1}$

RESUMO: Esta pesquisa tem como objetivo analisar o poema "A Billie Holiday, Cantora”, de Noémia de Sousa [1926-2003], que faz parte de uma coletânea de poemas do livro Sangue Negro publicado em 2001. Pretende-se observar a relação de sua forma estética enquanto conteúdo sedimentado. Em outras palavras, a intenção é verificar como os expedientes literários - pontuação, ritmo, verso, estrofação, figuras de linguagem, gramática, intertextualidade - criam sentido.

ABSTRACT: This study aims at analysing the poem "To Billie Holiday, Singer", by Noémia de Sousa [1926-2003], which is part of a collection of poems from the book Black Blood published in 2001. The intention is to observe the relation of its aesthetic form which is the sediment of content. In other words, we would like to verify how literary and extra-literary resources - such as pontuation, rhythmm, verse, stanza, figures of speech, grammar, intertextuality - make meaning.

PALAVRAS-CHAVE: História; Poesia de Combate; Política; Literatura; África.

KEYWORDS: History; War poetry; Politics; Literature; Africa.

1 É professor de literatura nas Faculdades Sumaré e UNIESP, é doutorando pelo Programa de Estudos Linguísticos e Literários em Inglês pela Faculdade de Filosofia, Letras e Ciências Humanas da Universidade de São Paulo - USP e mestre pelo mesmo programa. E-mail: marciodeus@usp.br 


\section{INTRODUÇÃO}

$\triangle$ arolina Noémia Abranches de Sousa Soares, ou simplesmente, Noémia de Sousa, foi alcunhada como "mãe dos poetas moçambicanos", recebendo esse título provavelmente pelo fato de sua ideologia política permear sua escritura, ficando difícil distinguir sua vida de sua obra; ambas eram pautadas pela vida em comunidade e engajamento político. Tanto isso é verdade que, a fim de fugir da censura moçambicana, ela fez uso do pseudônimo Vera Micaia. William Faulkner uma vez disse que o que a literatura faz é o mesmo que acender um fósforo no campo no meio da noite. Um fósforo não ilumina quase nada, mas nos permite ver quanta escuridão existe ao redor. Foi exatamente o que Noémia de Sousa fez e, com outros escritores que partilhavam de seus ideais, como José Craveirinha, Virgílio de Lemos e Sérgio Vieira, ela fez muitas estórias historicamente embasadas serem lidas e ouvidas; juntamente com esses autores, também participou do movimento chamado Negritude. ${ }^{2}$ Em 1951, ela foi presa e obrigada a se exilar em Portugal, onde não viria mais a escrever. Noémia alegava que perdera sua inspiração por estar distante de sua terra.

Essa importante autora africana de língua portuguesa escreveu o poema "A Billie Holiday, Cantora" em 24 de maio de 1949, período em que Moçambique ainda estava sob o controle de Salazar, mesmo após ter recebido uma determinação da ONU de iniciar uma política de descolonização em todo o mundo pós-Segunda Guerra Mundial. O Portugal de Salazar tinha grande interesse no território africano para realização das primeiras tentativas de prospecção petrolífera (1948 em Moçambique, 1957 em Angola). Como a metrópole lusitana não dispunha de capital para realizar tal empreitada, contava com os bancos americanos que estavam interessados em sua "fatia do bolo". Esse período coincide com o início das guerras de libertação em Angola e Moçambique 3 . 
O primeiro expediente com que o leitor tem contato no poema é o título: "A Billie Holiday, Cantora". A estrutura textual se assemelha à abertura do gênero epistolar e o destinatário de tal "correspondência" trata-se de uma pessoa pública - Billie Holiday [1915-1959]. É importante observar que se trata de uma mulher negra norte-americana que ganhou grande notoriedade ao interpretar a canção "Strange Fruit" ${ }^{4}$ em 1939 num clube noturno chamado Café Society em Nova lorque. A letra dessa canção denuncia os linchamentos a que os negros eram submetidos, em especial no sul dos Estados Unidos, e a fruta mencionada faz referência aos negros enforcados nas árvores, por isso ela é estranha e à fruta bíblica do conhecimento que traz a dor à humanidade. Tal canção irá fazer parte da luta do movimento pelos direitos civis e será também um grito de guerra. Assim como a canção interpretada por Billie Holiday, essa poesia noemiana também será um elemento de luta da Frente Liberal de Moçambique (FRELIMO).

Dentre todos os aspectos da poesia de combate, o que mais se destaca, e escandaliza, é a sua natureza radicalmente subversiva. Creio residir aí a fonte da paixão que leva, muitas vezes de forma apriorística, à sua negação ou aceitação, com evidente minimização de qualquer senso crítico. O processo de luta armada constitui ato supremo de rebeldia do dominado varrer pela força das armas a opressão. A consciência de estar agindo com a história - com a própria história recuperada - é algo constante na produção poética do período, configurando-se, assim a plena subversão: mostra-se possível derrotar o colonizador e, mais ainda, mostra-se possível arrancar-lhe seu instrumento mais terrível - a palavra, mais que isso, a palavra

$3 \mathrm{O}$ autor da letra foi Abel Meeropol, professor, escritor e compositor judeu norte-americano, que a publicou pela primeira vez em forma de poema sob o pseudônimo de Lewis Allen. Sua justificativa para sua escritura foi: "Eu escrevi "Strange Fruit" porque detesto linchamentos, detesto injustiça e detesto as pessoas que a perpetuam." (MARCOLICK, 2012, p.31) Meeropol era um ativista político. Um outro episódio de que ele é lembrado foi quando ocorreu a caça às bruxas - o macarthismo - nos EUA, e o casal Rosenberg foi acusado e sentenciado injustamente à morte. Após a execução, Meeropol e a esposa adotaram os filhos do casal. 
sacralizada na poesia - e usá-lo contra ele de modo drástico, acutilante. (SOUZA E SILVA, Manoel de, 1996, p.118-9)

Ainda no título do poema, o eu-lírico chama Billie Holiday de "cantora", ou seja, qualifica-a como uma trabalhadora da arte do canto, pode-se perceber que esse eu-lírico compartilha quase o mesmo ofício, o "cantar", tanto por meio das letras, quanto por meio de sua sonoridade, formando assim sua poesia. Escritura que, por conter um conteúdo altamente contrário ao regime do período, pode-se interpretar quase como um canto de guerra (a poesia de combate), exprimindo não só os anseios desse eu-lírico, mas de todos os africanos oprimidos. Noémia de Sousa fará uso de vários recursos literários para chegar a esse resultado, como estrofação, rima, pontuação, ritmo, categoria gramatical, imagens, figuras de linguagem, intertextualidade. $O$ intuito é que sejam abordados os elementos mais fáceis de observar para que a partir deles possam ser depreendido sentidos, mais do que se poderia pensar à primeira vista; correlacionando-se, assim, a dinâmica entre forma e conteúdo.

\section{A Billie Holiday, Cantora}

1. Era de noite e no quarto aprisionado em escuridão

2. apenas o luar entrara, sorrateiramente,

3. e fora derramar-se no chão.

4. Solidão. Solidão. Solidão.

5. E então,

6. tua voz, minha irmã americana,

7. veio do ar, do nada nascida da própria escuridão...

8. Estranha, profunda, quente,

9. vazada em solidão.

10. E começava assim a canção:

11. "Into each heart some rain must fall..."

12. Começava assim 
13. e era só melancolia

14. do princípio ao fim,

15. como se teus dias fossem sem sol

16. e a tua alma aí, sem alegria...

17. Tua voz irmã, no seu trágico sentimentalismo,

18. descendo e subindo,

19. chorando para logo, ainda trémula, começar rindo,

20. cantando no teu arrastado inglês crioulo

21. esses singulares "blues", dum fatalismo

22. rácico que faz doer

23. tua voz, não sei por que estranha magia,

24. arrastou para longe a minha solidão...

25. No quarto às escuras, eu já não estava só!

26. Com a tua voz, irmã americana, veio

27. todo o meu povo escravizado sem dó

28. por esse mundo fora, vivendo no medo, no receio

29. de tudo e de todos...

30. O meu povo ajudando a erguer impérios

31. e a ser excluído na vitória...

32. A viver, segregado, uma vida inglória,

33. de proscrito, de criminoso...

34. O meu povo transportando para a música, para a poesia, 35. os seus complexos, a sua tristeza inata, a sua insatisfação...

36. Billie Holiday, minha irmã americana,

37. continua cantando sempre, no teu jeito magoado

38. os "blues" eternos do nosso povo desgraçado...

39. Continua cantando, cantando, sempre cantando,

40. até que a humanidade egoísta ouça em ti a nossa voz,

41. e se volte enfim para nós,

42. mas com olhos de fraternidade e compreensão! 


\section{A ESCANSÃO OU METRIFICAÇÃO}

Sabe-se que para conseguir o efeito musical é preciso lançar mão de alguns expedientes como, por exemplo, a metrificação. Dentro do poema, observa-se que ora certa regularidade é extrapolada, como vemos nos versos um e dois, ora ela é seguida, como nos versos três e quatro. Tal quebra de expediente pode ser interpretada como uma forma de rebeldia, ao não fazer de seu poema um espelho da arte do colonizador. Isso fica nítido ao observarmos que, em certas estrofes, a metrificação é feita de forma impecável.

$\begin{array}{llllllllllllll}1 & 2 & 3 & 4 & 5 & 6 & 7 & 8 & 9 & 10 & 11 & 12 & 1314 & 15\end{array}$

$\mathrm{E} / \mathrm{ra} / \mathrm{de} /$ noi/te e /no /quar/to a/pri/sio/na/do em es/cu/ri/dão a/pe/nas/o / lu /ar/ en /tra /ra,/so/rra /tei/ ra/mente,

$\begin{array}{lllllllll}1 & 2 & 3 & 4 & 5 & 6 & 7 & 8 & 9\end{array}$

e /fo/ ra/ de /rra /mar/-se/no/chão.

So/li/ dão./ So /li /dão./ So /li/ dão.

Analisando a pontuação do poema, percebe-se o seguinte:

1. nem todos os versos são pontuados no fim, há 12 versos com essa característica;

2. Em 15 versos, há vírgulas fortes, isto é, forçando pausas acentuadas;

3. há oito versos terminados por reticências. Num total de 42, o índice é elevado - pouco menos de um quinto. Note-se que desses 8 versos, 3 estão presentes no quinto estribilho;

4. usa-se o ponto de exclamação, duas vezes no verso 25 e no último verso, 42. 
5. há três pontos finais.

Levando em consideração os itens 1 e 2, pode-se concluir que há um elevado número de enjambement, o que obriga o leitor a não realizar a leitura com a habitual pausa descendente no final, mas com entonação ascendente. $O$ efeito obtido é uma mescla de leitura que beira a uma narrativa em prosa, mas que, ao longo do poema, transborda sonoridade do princípio ao fim.

Em relação às rimas, a subversão do esquema tradicional ocidental deve ser analisada com cuidado. Embora, à primeira vista, possa não parecer haver qualquer regularidade, um olhar mais atento consegue chegar a algumas deduções significativas: a primeira estrofe apresenta a rima com "ão" nos versos 1, 3 e 4, sem contar com a repetição interna; similarmente, na estrofe seguinte, aparece nos versos 5, 7 e 9. Presente também na terceira estrofe, verso 10, surge de forma isolada na quarta, verso 24. No primeiro dístico, há mais uma ocorrência no verso 25. Na última estrofe, a rima que abre o poema, também o encerra, verso 42.

Ao destacar as palavras que compõem essas rimas, é notório que sua existência encadeada já produz uma pequena história sem conectivos: escuridão $>$ chão $>3$ x solidão $>$ então $>$ escuridão $>$ solidão $>$ canção > solidão > insatisfação > compreensão.

Assim como aparece a repetição das palavras "solidão" e "escuridão" no exemplo acima, outros vocábulos também aparecem na tessitura do poema mais de uma vez, como é o caso de "cantar", num total de seis. Tais ecos fazem a manutenção da sonoridade, distinguindo a poesia de Noémia de um texto em prosa.

\section{CATEGORIA GRAMATICAL E TEMPO VERBAL}

Constrói-se nessa lírica épica uma relação de intimidade entre o eu-lírico e Billie Holiday, ao serem usados o pronome possessivo "minha" e o substantivo "irmã", anunciando uma ideia de parentesco. Tal 
sugestão pode ser ratificada porque a África, na obra de Noémia de Sousa, muitas vezes é personificada na figura de mãe como no poema "Sangue negro".

Ao longo da poesia, os pronomes possessivos (tua, teu, minha, meu, suas, seus, nossa) vão ganhando importância semântica para compreensão. No excerto, "Tua voz, minha irmã americana,/veio do ar, do nada, nascida da própria escuridão..." indica que a canção, dessa cantora negra que é familiar ao eu-lírico, toma conta do ambiente. Essa voz soa de forma triste, por isso é usada a figura de linguagem comparação "como se teus dias fossem sem sol e a tua alma aí, sem alegria...". Mais uma vez o eu-lírico usa a imagem de parentesco, em "tua voz irmã, no seu trágico sentimentalismo,". Outros elementos que devem ser observados são um certo contraste entre "tua" e "seu", em que se pode interpretar como o primeiro sendo de fato algo de Billie Holiday, a voz, enquanto, o segundo, um sentimento mais distante da pessoa e, de certa forma, comunitário. Isso parece ser essencial, pois, o seguinte trecho "O meu povo transportando para a música, para poesia,/ os seus complexos, a sua tristeza inata, a sua insatisfação..." traz a ideia de que esse povo é do eu-lírico e que a tristeza e insatisfação são tanto de Billie Holiday quanto desse povo, sendo expressas na música e na poesia, tanto desse eu-lírico, quanto da cantora afrodescendente norte-americana. No último excerto dos pronomes destacados, os "blues" eternos do nosso povo desgraçado...", é perceptível que esse "nosso" refere-se a quem essa poesia é dirigida, Billie Holiday, ao eu-lírico, ao povo moçambicano e a todos os afrodescendentes.

De maneira análoga à cantora de blues norte-americana, o eu-lírico constrói sua própria música, para tanto, ele busca respaldo na sonoridade do poema, a repetição do ditongo "ão" [E w w] em palavras que terminam cada verso, como "escuridão", "chão", "solidão", "então", "canção", "insatisfação" "compreensão". Sendo substituído pelo fonema [u], em palavras como, "sentimentalismo", "subindo", "rindo", "crioulo", “fatalismo", “veio", "receio”, “todos”, “impé- 
rios”, “criminoso", “magoado”, "desgraçado”. A predominância de um fonema fechado permeia praticamente todas as estrofes, sendo possível, assim, afirmar que o texto traz um tom pesado e lamurioso por conta da repetição desse som.

\section{O CAMPO LEXICAL}

Se observado o campo lexical, nota-se o uso de termo que lembram fatores negativos: noite, escuridão, solidão, melancolia, sem sol, fatalismo, medo, receio, criminoso, vida inglória, tristeza inata, insatisfação, magoado, desgraçado, egoísta. Esses elementos lexicais são importantes para complementar a ideia da sonoridade da poesia.

Em relação aos personagens desse poema lírico-épico, identifica-se Billie Holiday - a cantora americana, cantando seu blues que comove o eu-lírico que está provavelmente num ambiente escuro. Há o povo do eu-lírico escravizado, que constrói impérios e não tem direito a eles. Por fim, temos uma humanidade egoísta que pode escutar as músicas de Holiday, e, talvez por isso, o eu-lírico pede para que ela também cante sobre "nós", não com pena, "mas com olhos de fraternidade e compreensão".

Seguindo essa lógica, o termo blues aparece duas vezes na poesia: "esses singulares 'blues', dum fatalismo rácico que faz doer/tua voz" e "no teu jeito magoado/os 'blues' eternos do nosso povo desgraçado...". A palavra blues, segundo a primeira acepção do dicionário online Aulete, significa, "Música do folclore negro norte-americano, originária do spiritual, em tom menor e geralmente de caráter melancólico e andamento moderado." Nessas duas entradas no poema, os significados são distintos. No primeiro, trata-se da acepção dicionarizada, mas no segundo não engloba apenas o negro norte-americano, mas também o africano e todos os seus descendentes. 


\section{A ESTROFAÇÃo}

É interessante observar que o poema está dividido em 6 estrofes e dois dísticos. Primeiramente, são apresentadas cinco estrofes a partir do seguinte esquema:

Primeira estrofe: Um eu-lírico se apresenta num quarto escuro completamente sozinho.

Segunda estrofe: A voz de Billie Holiday quebra esse silêncio.

Terceira estrofe: Apresenta o motivo triste da canção que está sendo escutada.

Quarta estrofe: São observadas as idiossincrasias da voz de Billie Holiday, elas estão ligadas à raça - "fatalismo rácico" e "teu arrastado inglês crioulo".

Quinta estrofe: Por meio da voz de Billie Holiday, houve uma grande reunião entre a cantora norte-americana, o povo escravizado, segregado e obrigado a erguer impérios relegado a "uma vida inglória".

Primeiro dístico: A "insatisfação" e "a tristeza inata" foram transformadas em poesia e música. A primeira conclusão a que o eu-lírico chega.

Sexta estrofe: Billie Holiday precisa continuar cantando as mágoas e os "blues" eternos do nosso povo desgraçado "até que a humanidade egoísta ouça" nela a voz desse povo oprimido.

Segundo e último dístico: convocação para que Billie Holiday olhe para esse povo, "mas com olhos de fraternidade e compreensão". Entretanto, não se pode esquecer que essa é uma "correspondência" aberta em que não só Holiday precisa ter essa atitude, mas o leitor também.

\section{A INTERTEXTUALIDADE}

A canção ouvida pelo eu-lírico é "Into each heart some rain must fall...", numa tradução livre, "Em cada coração alguma chuva deve cair", escrita em 1944 e cantada pelo dueto The Ink Spots, com participação especial de Bill Kenny e Ella Fitzgerald. Importante notar que todos eram afrodescendentes. 


\section{Into Each Life Some Rain Must Fall}

Into each life some rain must fall

But too much is falling in mine

Into each heart some tears must fall

But some day the sun will shine

Some folks can lose the blues in their hearts

Em cada vida deve chover um pouco

Em cada vida deve chover um pouco

Mas está chovendo demais na minha

Em cada coração algumas lágrimas devem cair

Mas algum dia o sol brilhará

Algumas pessoas podem perder o "blues" em seus corações

[...] (Tradução minha)

Observa-se que a letra dessa canção é uma metáfora em relação à situação da África, em que algumas pessoas podem perder as esperanças, mas há a chance de mudança. Essa metáfora não deixa também de ser uma intertextualidade, pois o refrão da canção faz parte do poema "The Rainy day", de Henry Wadsworth Longfellow [1807-1882]".

\section{The Rainy day}

$[\ldots]$

Be still, sad heart, and cease repining;

Behind the clouds is the sun still shining;

Thy fate is the common fate of all, Into each life some rain must fall, Some days must be dark and dreary.

4 LONGFELLOW, Henry Wadsworth. "The Rainy Day". In: All Poetry. Disponível em: <http:// allpoetry.com/The-Rainy-Day>. Acesso em: 10 maio 2016. 


\section{O dia chuvoso}

$[\ldots]$

Fique quieto, coração triste, e pare de lamentar; Atrás das nuvens está o sol ainda brilhando está;

Vosso destino é o destino comum de todos,

Em cada vida alguma chuva deve cair,

Alguns dias devem ser escuros e obscuros.

(Tradução minha)

Contrastivamente, na poesia longfellowiana, o eu-lírico parece tratar das preocupações do indivíduo e não de um coletivo. Além disso, nessa mimetização artística, o sol sempre está presente, porém ele não é visto. De maneira análoga, o eu-lírico do poema noemiano apresenta o recurso de comparação fazendo similar observação: "como se teus dias fossem sem sol/ e a tua alma aí, sem alegria...", significando que talvez os dias de Billie Holiday não sejam de fato assim; entretanto, nesse último caso, a tessitura poética constrói uma imagem tratando de um sentimento racial, enquanto na poesia de Longfellow pode ter diferentes motivações (amor, morte, perda, melancolia, etc).

Ainda sobre a canção, o que chama a atenção é o fato de ela não ter sido tocada propositalmente pelo eu-lírico, mas ela "veio do ar, do nada, nascida da própria escuridão..." invadindo o quarto e a solidão ali presente. Essa voz negra, que arrasta para longe a solidão do eu-lírico, pode ser entendida como um regresso desse afrodescendente à sua terra mãe. Nessa lógica, o eu-lírico parece convocar seus "irmãos" afrodescendentes a engrossar a voz para uma luta por justiça e reconhecimento.

\section{CONSIDERAÇÕES FINAIS}

A vida de Noémia de Sousa não diferia de sua arte, que pode ser categorizada como engajada. A dialética entre forma e conteúdo de seu 
poema transborda em todas as direções uma denúncia do que os africanos historicamente sofrem desde o contato com o colonizador. Utilizando-se do gênero epistolar como pretexto, esse poema, por meio de recursos como enjambement, traz um formato de prosa, mas não devemos nos levar pelas aparências, pois os jogos de palavras dão ao texto uma grande miríade interpretativa. Nesse estudo apresentamos uma possibilidade, sem a pretensão de esgotar suas possibilidades de leitura.

Procurou-se, neste estudo, por meio minuciosa descrição e análise dos elementos constitutivos literários e extraliterários mobilizados por essa poetisa moçambicana, chegar a uma possível leitura dessa obra de arte - uma poesia de combate, ora subvertendo ou ignorando a metrificação rigorosa comumente usada pelo colonizador, ora utilizando de expedientes sonoros a fim de ecoar a lamúria de um povo oprimido.

Ao analisar-se o campo semântico de "A Billie Holiday, cantora", percebeu-se que a cuidadosa escolha lexical edifica um cenário desolador. Entretanto, não é essa mensagem que parece interessar ao eu-lírico. Por meio da intertextualidade, como na apropriação da música "The rainy day", somos levados a uma analogia entre situações de transtorno e caos, de um lado, vivenciada por indivíduos apaixonados, e do outro, pelo povo moçambicano apaixonado por sua terra. O sol um dia vai voltar a brilhar. Tal estado de calmaria, no entanto, seria alcançável somente através de uma ação conjunta entre todos os africanos e seus descendentes. Desses últimos não se busca pena ou compaixão, mas fraternidade e indignação para que sejam aliados na frente de batalha, usando o que têm à mão como arma, mesmo que essa arma seja o seu canto.

A esperança do eu-lírico está na aposta de que a mudança é possível: esse poema é mais um fósforo na escuridão que convoca outros para denunciar e mostrar quanta escuridão existe em Moçambique e na África, como resultado de uma herança indesejável histórica deixada pelo colonizador. 


\section{REFERÊNCIAS BIBLIOGRÁFICAS}

ALBINO, Inocêncio. “Revitalizar o sangue negro!”. In: @Verdade Jornal Gratuito. [s.I.] 6 out. 2011. Disponível em: <http://www.verdade.co.mz/ cultura/22558-revitalizar-o-sangue-negro >. Acesso em: 05 maio 2016. CANDIDO, Antonio. Na sala de aula: caderno de análise literária. 8.ed. São Paulo: Ática, 1998.

CANDIDO, Antonio. O estudo analítico do poema. 3.ed. São Paulo: Humanitas, 1996.

DE SOUSA, Noémia. Sangue negro. Associação dos Escritores Moçambicanos: s.l., 2001, p. 135-6.

GOMES, Simone Caputo. "Poesia moçambicana e negritude: caminhos para uma discussão". In: Revista Via Atlântica. São Paulo: USP, 2011. Disponível em: < http://www.revistas.usp.br/viaatlantica/article/viewFile/50460/54572>. Acesso em: 11 maio 2016.

LONGFELLOW, Henry Wadsworth. "The Rainy Day". In: All Poetry. Disponível em: <http://allpoetry.com/The-Rainy-Day>. Acesso em: 10 maio 2016.

MARGOLICK, David. Billie Holiday e a biografia de uma canção Strange Fruit. São Paulo: CosacNaify, 2012.

MAZRUI, A. \& WONDJI, C. (ed.) História geral da África, VIII: África desde 1935. Brasília: UNESCO, 2010, p. 123-150. Disponível em: <http://www. dominiopublico.gov.br/download/texto/ue000325.pdf> . Acesso em: 12 maio 2016.

SOUZA E SILVA, Manoel de. Do alheio ao próprio a poesia em Moçambique. São Paulo: Edusp,1996. 